\title{
EZH2 Inhibitor SHR2554
}

National Cancer Institute

\section{Source}

National Cancer Institute. EZH2 Inhibitor SHR2554. NCI Thesaurus. Code C158742.

An orally available selective inhibitor of the histone lysine methyltransferase (HMT) enhancer of zeste homolog 2 (EZH2), with potential antineoplastic activity. Upon oral administration, EZH2 inhibitor SHR2554 selectively targets, binds to and inhibits the activity of EZH2. Inhibition of EZH2 specifically prevents the methylation of histone $\mathrm{H} 3$ on lysine 27 (H3K27). This decrease in histone methylation alters gene expression patterns associated with cancer pathways and results in decreased proliferation of EZH2-expressing cancer cells. EZH2, an HMT class enzyme and the catalytic subunit of the polycomb repressive complex 2 (PRC2), is overexpressed or mutated in a variety of cancer cells and plays a key role in tumor cell proliferation; its expression is correlated with tumor initiation, progression, stem cell self-renewal, migration and angiogenesis. 